IMECE2008-66518

\title{
APPLICATION OF THE RAPID UPDATE CYCLE (RUC) TO AIRCRAFT FLIGHT SIMULATION
}

\author{
Yan Zhang \\ EG\&G Technical Services \\ Cambridge, Massachusetts, USA
}

\author{
Seamus McGovern \\ U.S. DOT National Transportation Systems Center \\ Cambridge, Massachusetts, USA
}

\begin{abstract}
An aircraft flight simulation model under development aims to provide a computer simulation tool to investigate aircraft flight performance during en route flight and landing under various atmospherical conditions [1]. Within this model, the air pressure and temperature serve as important parameters for deriving the true airspeed (TAS). Also important are the wind speed and direction, which will be direct inputs for the flight simulation model.

In this paper, the Rapid Update Cycle (RUC) data, provided hourly by the National Centers for Environmental Prediction (NCEP) and the National Oceanic and Atmospheric Administration (NOAA) are used to derive the atmospherical parameters. We relate the pressure to the geodetic altitude by using the geopotential height from the RUC data and the theoretical model. Then the resultant pressure as a function of the geodetic altitude is used to retrieve other parameters such as the temperature and wind velocity by multi-dimensional interpolation. Airplane flights simulated by the X-Plane ${ }^{\circledR}$ simulator with the input of the RUC data are demonstrated.
\end{abstract}

\section{INTRODUCTION}

An aircraft flight simulation model takes atmospherical data as part of the input for its flight dynamics and cockpit display modeling. Among these data, the air pressure serves as an important parameter for deriving the true airspeed (TAS) [and ultimately the ground speed (GS)] from the indicated airspeed (IAS). The wind speed and direction are also important factors that directly affect the airplane's flight dynamics.

The Rapid Update Cycle (RUC) data is adopted in this paper to obtain the most accurate and realistic atmospherical data $[2,3]$. The RUC runs operationally at the National Cen- ters for Environmental Prediction (NCEP), the National Oceanic and Atmospheric Administration (NOAA), and produces numerical weather prediction data hourly with horizontal spatial resolution of $20 \mathrm{~km}$ or $13 \mathrm{~km}$, and vertical pressure resolution of 25 $\mathrm{mb}$ [4]. The RUC provides a broad range of environmental parameters including, as a function of 37 constant pressure levels, the geopotential height, temperature, relative humidity, horizontal wind velocity, and pressure vertical velocity. However, the air pressure is not provided in RUC data in terms of the geodetic location, rather it is used as the reference to specify other parameters such as the geopotential height, temperature, wind velocity, etc., preventing the RUC data to be directly used for a given geodetic location of an aircraft.

In the paper, the pressure is retrieved for a given geodetic location by using the geopotential height from the RUC data and a theoretical gravity model [5]. Then the resultant pressure is used to extract other RUC data, hence they can be represented as a function of a geodetic location. In addition, formulations and procedures of retrieving/processing the RUC data for the need of aircraft flight simulation are presented, including the coordinate transformation, geopotential height modeling, data interpolation, and time averaging. We will also demonstrate airplane's flight performance by using the existing aircraft flight simulator, the X-Plane ${ }^{\circledR}$ V8.40 with the input of the RUC data.

\section{DESCRIPTION OF THE SIMULATION ALGORITHMS}

The functionality of the aircraft simulation with the input of environmental data from RUC is illustrated by the information flowchart shown in Fig. 1. The outputs from the aircraft flight model are the flight time $t$ and the aircraft's "true" location (geodetic latitude $\phi$, longitude $\lambda$, and altitude $h$ ). The RUC data are available hourly, therefore we need to read the RUC data at 


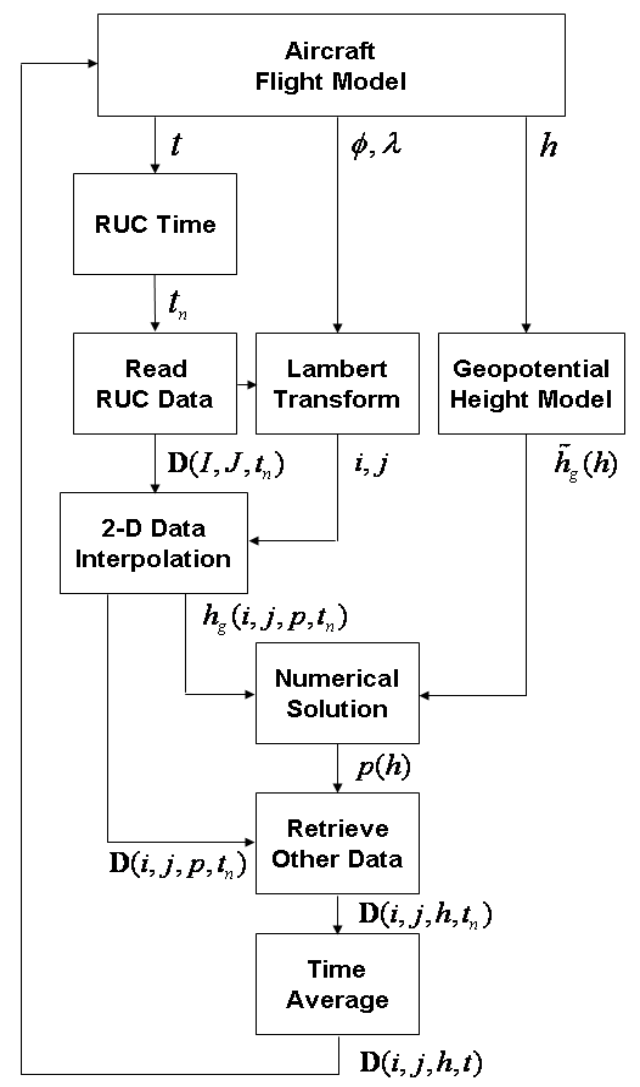

Figure 1. THE INFORMATION FLOWCHART OF THE AIRCRAFT FLIGHT SIMULATION WITH THE INPUT OF THE RUC DATA. THE DESCRIPTION OF THE SYMBOLS AND THE FUNCTIONS CAN BE FOUND IN THE NOMENCLATURE AND IN THE TEXT.

two adjacent hours $t_{n}$ and $t_{n+1}$, where $t_{n}<t<t_{n+1}$, then process the RUC data for the time $t$ by data interpolation/averaging. The details of the algorithms are described in the following.

\section{RUC Data Retrieval}

The RUC data, archived in the GRIB format [6] in the NOAA National Operational Model Archive and Distribution System (NOMADS) [7], can be downloaded for a particular RUC Time specified by the year, month, day, and UTC hour, and decoded by using the modified $\mathrm{C} / \mathrm{C}++$ code originally developed by Ebisuzaki [8]. For example, for the UTC time 16:00, May 1st, 2007, the RUC data with the file name ruc2_252_20070501_1600_000.grb (where the number ' 252 ' specifies the particular grid with $20 \mathrm{~km}$ resolution [7]) can be found and downloaded from the directory $200705 / 20070501 /$ in the web site http://nomads.ncdc.noaa.gov/data/ruc/. In the RUC data which contains 315 data records, the geopotential height (record \# 1-37), temperature (record \# 38-74), and wind (record \#112-185) will be used in this paper.
The geopotential height, temperature, and easterly and northerly wind velocities have, respectively, 37 records at different pressure levels from $1,000 \mathrm{mb}$ to $100 \mathrm{mb}$ with decreasing step of $25 \mathrm{mb}$. These data for a particular location in the airspace are projected to the Lambert conformal surface, the cone tangent to the spherical Earth with the apex over the North Pole. The parameters for the Lambert conformal projection, such as the grid length $d x$ and $d y$, longitude of the reference meridian $\lambda_{0}^{\prime}$, latitude of the tangent point $\phi_{0}^{\prime}$, location of the first grid point $\left(\phi_{1}^{\prime}\right.$ and $\left.\lambda_{1}^{\prime}\right)$, the radius of the spherical Earth, as listed in Tab. 1, are defined in the RUC data and are useful for coordinate transformations as shown later in the paper.

Lambert Coordinate Transformation. The RUC provides the data in the Lambert conformal projection with a uniform grid $(I, J)$. In order to achieve fast data interpolation by adopting the integers $I$ and $J$ as the indices of the memory addresses that contain the data, we convert airplane's geodetic position (latitude, longitude, and altitude), output from the aircraft simulation model, to the Lambert coordinates.

First, we convert the aircraft's geodetic location to the geocentric location. Given the geodetic latitude $(\phi)$, longitude $(\lambda)$ and geodetic height $(h)$, the geocentric latitude $\left(\phi^{\prime}\right)$, longitude $\left(\lambda^{\prime}\right)$ and radius $(R)$ can be solved in closed form. By considering the Earth as an ellipsoid with semi-major axis $a$ and flattening $f$ [thus the semi-minor axis can be computed by $b=a(1-f)$ ], and defining the first eccentricity squared as $e^{2}=2 f-f^{2}$, the Cartesian coordinates of a point $(X, Y, Z)$ in the Earth-Centered Earth-Fixed (ECEF) frame can be expressed both geocentrically and geodetically as

$$
\left\{\begin{array}{l}
X=R \cos \phi^{\prime} \cos \lambda^{\prime}=\left(\frac{a}{\chi}+h\right) \cos \phi \cos \lambda \\
Y=R \cos \phi^{\prime} \sin \lambda^{\prime}=\left(\frac{a}{\chi}+h\right) \cos \phi \sin \lambda \\
Z=R \sin \phi^{\prime}=\left(\frac{a\left(1-e^{2}\right)}{\chi}+h\right) \sin \phi
\end{array}\right.
$$

where $\chi=\sqrt{1-e^{2} \sin ^{2} \phi}$. Eliminating $R$ and $\lambda^{\prime}$ (which is equal to $\lambda$ ), we get the equation that can be used to solve $\phi^{\prime}$ by providing $\phi$ and $h$ :

$$
\phi^{\prime}=\tan ^{-1}\left[\left(1-\frac{a}{a+h \chi} e^{2}\right) \tan \phi\right]
$$

Next, we convert the geocentric latitude and longitude to the coordinates in the Lambert conformal projection. Consider $n^{*}=$ $H \sin \phi_{0}^{\prime}$ to be the constant of the cone for the Lambert conformal projection where $H=1$ or -1 when the apex is over the North or South Pole, respectively. In terms of the pixel index number 
$(i, j)$ of the image, the local coordinates $(x, y)$ is expressed by

$$
\left\{\begin{array}{l}
x=(i-1) d x+x_{1} \\
y=-(j-1) d y+y_{1}
\end{array}\right.
$$

where $d x$ and $d y$ are grid lengths in $x$ and $y$-direction, respectively, and the indices $(i, j)$ do not have to be integers. The local coordinates of the left lower pixel $\left(x_{1}, y_{1}\right)$ are calculated from

$$
\left\{\begin{array}{l}
x_{1}=\frac{\sigma_{1} R_{0} \cos \phi_{1}^{\prime}}{n^{*}} \sin \left[n^{*}\left(\lambda_{1}^{\prime}-\lambda_{0}^{\prime}\right)\right] \\
y_{1}=\frac{\sigma_{1} R_{0} \cos \phi_{1}^{\prime}}{n^{*}} \cos \left[n^{*}\left(\lambda_{1}^{\prime}-\lambda_{0}^{\prime}\right)\right]
\end{array}\right.
$$

In addition, the image scale of the Lambert conformal projection, $\sigma_{1}$, is defined by,

$$
\sigma_{1}=\left(\frac{\cos \phi_{0}^{\prime}}{\cos \phi_{1}^{\prime}}\right)^{1-n^{*}}\left(\frac{1+n}{1+H \sin \phi_{1}^{\prime}}\right)^{n^{*}}
$$

where $\left(\phi_{1}^{\prime}, \lambda_{1}^{\prime}\right)$ depicts the geocentric coordinates of the left lower pixel. The detail derivation for Eqns. (4) and (5) can be found in [9]. Given the geocentric coordinates $\left(\phi^{\prime}, \lambda^{\prime}\right)$, we define the polar angle,

$$
\theta=n^{*}\left(\lambda^{\prime}-\lambda_{0}^{\prime}\right)
$$

and the polar range,

$$
\rho=\frac{\left(\cos \phi_{0}^{\prime}\right)^{\left(1-n^{*}\right)}\left(1+n^{*}\right)}{\left(n^{*} / R_{0}\right)} \tan ^{2}\left(\frac{\pi}{4}-\frac{H \phi^{\prime}}{2}\right)
$$

the local coordinates $(x, y)$ can be expressed as

$$
\left\{\begin{array}{l}
x=\rho \sin \theta \\
y=\rho \cos \theta
\end{array}\right.
$$

By solving Eq. (3), we found the indices $(i, j)$ for the Lambert conformal projection as

$$
\left\{\begin{array}{l}
i=\left(\rho \sin \theta-x_{1}\right) / d x+1 \\
j=-\left(\rho \cos \theta-y_{1}\right) / d y+1
\end{array}\right.
$$

2-D Data Interpolation. Upon solving the grid indices $(i, j)$ in the Lambert conform project for the aircraft location as shown in Eqn. (9), four RUC data points with indices $(I, J),(I+$ $1, J),(I+1, J+1)$, and $(I, J+1)$, respectively, where $I<i<I+1$
Table 1. PARAMETERS IN RUC FOR LAMBERT CONFORMAL PRO-

\begin{tabular}{|c|c|c|}
\hline Parameter & Notation & Value \\
\hline $\begin{array}{c}\text { Radius of the } \\
\text { Spherical Earth }\end{array}$ & $R_{0}$ & $6.36747 \times 10^{6} \mathrm{~m}$ \\
\hline $\begin{array}{c}\text { Latitude of First } \\
\text { Grid Point }\end{array}$ & $\phi_{1}^{\prime}$ & $16.281000^{\circ}$ \\
\hline $\begin{array}{c}\text { Longitude of First } \\
\text { Grid Point }\end{array}$ & $\lambda_{1}^{\prime}$ & $233.862000^{\circ}$ \\
\hline $\begin{array}{c}\text { Latitude of the Point } \\
\text { at Which the Secant } \\
\text { Cone Tangent to } \\
\text { the Spherical Earth }\end{array}$ & $\phi_{0}^{\prime}$ & $25^{\circ}$ \\
\hline $\begin{array}{c}\text { Longitude of the } \\
\text { Reference Meridian }\end{array}$ & $\lambda_{0}^{\prime}$ & $265^{\circ}$ \\
\hline $\begin{array}{c}\text { X-direction Grid Length } \\
\text { Y-direction Grid Length }\end{array}$ & $d x$ & $20,318.000 \mathrm{~m}$ \\
\hline
\end{tabular}

and $J<j<J+1$, are used for the 2-D data interpolation. We first determine whether the point $(i, j)$ is in the triangle 'A' with vertices $(I, J),(I+1, J)$, and $(I+1, J+1)$ or in the triangle ' $\mathrm{B}$ ' with vertices $(I+1, J+1),(I, J+1)$, and $(I, J)$ by checking the ratio $r=(j-J) /(i-I)$. It follows that, if $r<1$ then the point $(i, j)$ is in triangle 'A', if $r>1$ then the point is in triangle ' $\mathrm{B}$ ', otherwise it is on the edges. Notice that we choose a triangle as the basis for the 2-D data interpolation due to the fact that three points define a surface plane. In the triangle with the coordinates of the three vertices re-labeled as $\left(I_{1}, J_{1}\right),\left(I_{2}, J_{2}\right)$, and $\left(I_{3}, J_{3}\right)$, and the associated RUC data denoted as $D_{1}, D_{2}$, and $D_{3}$, respectively, the value of the RUC data at $(i, j)$ can be calculated by

$$
D(i, j)=A i+B j+C
$$

where $A, B$, and $C$ are the constants that can be solved by the Cramer's rule for the system of linear equations. As a result, the constants are

$$
A=A^{\prime} / D^{\prime}, \quad B=B^{\prime} / D^{\prime}, \quad C=C^{\prime} / D^{\prime}
$$

where the determinants of the matrix coefficients are calculated by

$$
\begin{array}{ll}
A^{\prime}=\left|\begin{array}{lll}
D_{1} & J_{1} & 1 \\
D_{2} & J_{2} & 1 \\
D_{3} & J_{3} & 1
\end{array}\right| & B^{\prime}=\left|\begin{array}{lll}
I_{1} & D_{1} & 1 \\
I_{2} & D_{2} & 1 \\
I_{3} & D_{3} & 1
\end{array}\right| \\
C^{\prime}=\left|\begin{array}{lll}
I_{1} & J_{1} & D_{1} \\
I_{2} & J_{2} & D_{2} \\
I_{3} & J_{3} & D_{3}
\end{array}\right| & D^{\prime}=\left|\begin{array}{lll}
I_{1} & J_{1} & 1 \\
I_{2} & J_{2} & 1 \\
I_{3} & J_{3} & 1
\end{array}\right|
\end{array}
$$


Table 2. SELECTED PARAMETERS FROM WGS84

\begin{tabular}{|c|c|c|}
\hline Parameter & Notation & Value \\
\hline Semi-Major Axis & $a$ & $6,378,137.0 \mathrm{~m}$ \\
\hline $\begin{array}{l}\text { Reciprocal of } \\
\text { Flattening }\end{array}$ & $1 / f$ & 298.257223563 \\
\hline $\begin{array}{c}\text { Earth's Gravitational } \\
\text { Constant Including } \\
\text { Atmosphere }\end{array}$ & $G M$ & $\begin{array}{c}3,986,004.418 \times 10^{8} \\
\mathrm{~m}^{3} / \mathrm{s}^{2}\end{array}$ \\
\hline $\begin{array}{c}\text { Angular Velocity of } \\
\text { the Earth }\end{array}$ & $\omega$ & $\begin{array}{c}7,292,115.0 \times 10^{-11} \\
\mathrm{rad} / \mathrm{s}\end{array}$ \\
\hline $\begin{array}{l}\text { First Eccentricity } \\
\text { Squared }\end{array}$ & $e^{2}$ & $6.69437999014 \times 10^{-3}$ \\
\hline $\begin{array}{c}\text { Normal Gravity at } \\
\text { Equator (on Ellipsoid) }\end{array}$ & $g_{e}$ & $9.7803253359 \mathrm{~m} / \mathrm{s}^{2}$ \\
\hline $\begin{array}{l}\text { Normal Gravity at the } \\
\text { Pole (on Ellipsoid) }\end{array}$ & $g_{p}$ & $9.8321849378 \mathrm{~m} / \mathrm{s}^{2}$ \\
\hline $\begin{array}{l}\text { Standard Gravity } \\
\text { at the Mean Sea Level }\end{array}$ & $g_{0}$ & $9.80665 \mathrm{~m} / \mathrm{s}^{2}$ \\
\hline
\end{tabular}

Geopotential Height Model. To relate the geopotential height of the RUC data to the geodetic height, we use the theoretical normal gravity model [5] that expresses, in closed form, the magnitude of the gradient of the normal potential function (or gravity $g$ ), on, as well as above, the surface of the ellipsoid.

On the surface of the ellipsoid, the gravity is given by

$$
g=g_{e} \frac{1+k \sin ^{2} \phi}{\chi}
$$

where $\phi$ is the geodetic latitude, and $k=b g_{p} /\left(a g_{e}\right)-1$ with $g_{e}$ and $g_{p}$ representing the theoretical normal gravity at the equator and poles, respectively. The commonly used parameters for the theoretical normal gravity are defined in the WGS84 model [10] as summarized in Tab. 2.

Above the surface of the ellipsoid, when the geodetic height $h$ is small (e.g., $h<20,000 \mathrm{~m}$ ) as being interested in this paper, the normal gravity can be found by using the truncated Taylor series expansion up to the second order as shown in detail in [5]:

$$
g_{h}=g\left[1-\frac{2}{a}\left(1+f+m-2 f \sin ^{2} \phi\right) h+\frac{3}{a^{2}} h^{2}\right]
$$

where $m=\omega^{2} a^{2} b / G M$.

Consider the gravity $\left(g_{h}\right)$ as a function of the geodetic height $(h)$, the gravitational potential is defined as

$$
\Phi=\int_{h_{0}}^{h} g_{h}\left(\phi, h^{\prime}\right) d h^{\prime}
$$

and the geopotential height is denoted as

$$
\tilde{h}_{g}=\Phi / g_{0}
$$

where $g_{0}$ is the standard gravity at the mean sea level, and $h_{0}$ is the geoid undulation (the geodetic height of the mean sea level relative to the ellipsoid). As an example, the 1-degree data for $h_{0}$ are available in the MATLAB Mapping Toolbox [11]. Upon conducting the integration in Eqn. (16), the geopotential height is found to be

$$
\tilde{h}_{g}=H_{g}(\phi, h)-H_{g}\left(\phi, h_{0}\right)
$$

where

$$
H_{g}(\phi, h)=h \frac{g}{g_{0}}\left[1-\frac{1+f+m-2 f \sin ^{2} \phi}{a} h+\frac{1}{a^{2}} h^{2}\right]
$$

Numerical Solution for the Pressure. We assume that the geopotential heights of the RUC data, denoted by $h_{g}\left(i, j, p_{\ell}\right)$ for pressure level $\ell$, where $\ell=1, \cdots, 37$, have been obtained for aircraft's location specified by the indices $(i, j)$ in the corresponding Lambert coordinates. By comparing the theoretical geopotential height $\tilde{h}_{g}(h)$ with $h_{g}\left(i, j, p_{\ell}\right)$ from the RUC data, we can locate the pressure level $\ell$ by data searching, i.e.,

$$
h_{g}\left(i, j, p_{\ell}\right)<\tilde{h}_{g}(h)<h_{g}\left(i, j, p_{\ell+1}\right)
$$

Hence the pressure for the given altitude $h$ can be calculated by linear interpolation as

$$
p(h)=p_{\ell}+\frac{p_{\ell+1}-p_{\ell}}{h_{g}\left(i, j, p_{\ell+1}\right)-h_{g}\left(i, j, p_{\ell}\right)}\left(\tilde{h}_{g}(h)-h_{g}\left(i, j, p_{\ell}\right)\right)
$$

Retrieve Other RUC Data. The RUC's volume data (the data at various height) are presented as a function of the pressure. Once the pressure for aircraft's location (latitude, longitude, and altitude) is obtained as described in the previous section, other RUC's volume data, $\mathbf{D}(i, j, p)$, such as the air temperature and wind speed, can be retrieved by similar data interpolation method, i.e.,

$$
\mathbf{D}(i, j, h)=\mathbf{D}\left(i, j, p_{\ell}\right)+\frac{\mathbf{D}\left(i, j, p_{\ell+1}\right)-\mathbf{D}\left(i, j, p_{\ell}\right)}{p_{\ell+1}-p_{\ell}}\left(p-p_{\ell}\right)
$$

Time Average. Following the data retrieval for the RUC data at time $t_{n}$, the RUC data at time $t_{n+1}$ can also be found with 
the same procedure, where for the time of interest $t$, we assume $t_{n}<t<t_{n+1}$. Hence the RUC data at time $t$ can be calculated by time averaging as

$$
\mathbf{D}(i, j, h, t)=(1-\alpha) \mathbf{D}\left(i, j, h, t_{n}\right)+\alpha \mathbf{D}\left(i, j, h, t_{n+1}\right)
$$

where $\alpha$ is the weighting factor expressed by

$$
\alpha=\frac{t-t_{n}}{t_{n+1}-t_{n}}
$$

\section{Aircraft Flight Model}

The aircraft flight model used in this paper to test the RUC data is the X-Plane ${ }^{\circledR}$ V8.40 developed by Laminar Research [12]. Based on the blade element theory, the XPlane ${ }^{\circledR}$ calculates forces for small elements broken down from the aircraft geometry, then figures out the motion and position of the aircraft. In addition, the X-Plane ${ }^{\circledR}$ provides the interface for users to execute the flight commands by writing the plug-in code (see [13] for details). The RUC wind data can be sent to the X-Plane ${ }^{\circledR}$ by overwriting to the data "sim/weather/wind_speed_kt" for the absolute value of the wind speed in kt and "sim/weather/wind_direction_degt" for the direction in degrees from which the wind is flowing with respect the true north clockwise.

In this paper, we develop a simple plug-in code to command the B747-400 model for automatic flight, including takeoff, inflight, and ILS landing. As an example for the simulation, we choose the Runway 22L at the Boston Logan Airport for takeoff and landing. The flight commands are shown in Tab. 3.

\section{SIMULATION EXAMPLES}

We show the simulation results for B747-400 flight at the time in the months of February, May, August, and November, representing 4 different weather conditions in Winter, Spring, Summer, and Fall, respectively. The year of the flights is set as 2007, and the flight starts at UTC time 16:00 in the first day of the month.

The flight commands as shown in Tab. 3 are designed for the zero-wind condition, including computer-simulated pilot actions and autopilot. With the update rate as one callback in every two seconds, the plug-in program reads the airplane's flight time $t$, latitude $\phi$, longitude $\lambda$, and altitude $h$, and uses them as input parameters to retrieve the RUC data as illustrated in Fig. 1.

For data interpolation, both the RUC data at UTC time 16:00 and 17:00 must be read and processed. Figure 2 shows the example of the RUC data for the geopotential height on the pressure level of $800 \mathrm{mb}$ at the UTC time of 16:00, May 1st, 2007. The geopotential heights at various pressure levels $(1,000 \mathrm{mb}-$ $100 \mathrm{mb}$ with decreasing step of $25 \mathrm{mb}$ ) are available in the RUC data with the record number from 1 to 37 . The horizontal and
Table 3. PLUG-IN COMMANDS FOR B747-400 USING X-PLANE ${ }^{\circledR}$

\begin{tabular}{|c|c|}
\hline Time (sec) & Command \\
\hline & Takeoff \\
\hline 0 & set flight director on 'auto' \\
\hline \multirow[t]{6}{*}{5} & dial AP magnet heading to ' 216 ' (deg-ang) \\
\hline & set AP heading 'on' \\
\hline & release brake \\
\hline & set flaps down by ' 2 ' \\
\hline & dial indicated airspeed (IAS) to '310’ (kt) \\
\hline & set AP auto-throttle 'on' \\
\hline 50 & set flaps up by ' 2 ' \\
\hline \multirow[t]{2}{*}{60} & retract landing gear \\
\hline & In-Flight \\
\hline 60 & dial AP ALT to ' $10,000 ’(\mathrm{ft})$ \\
\hline 61 & set AP ALT 'on' \\
\hline 70 & dial AP magnet heading to '306' (deg-ang) \\
\hline 100 & dial AP magnet heading to ' 36 ' (deg-ang) \\
\hline 300 & dial AP magnet heading to ' 126 ' (deg-ang) \\
\hline \multirow[t]{2}{*}{330} & dial AP magnet heading to ' 190 ' (deg-ang) \\
\hline & ILS Landing \\
\hline 5 & dial NAV1 to '11030' (110.30 MHz) \\
\hline 200 & set AP vertical speed (V/S) 'on' \\
\hline 201 & dial AP V/S to ' $-2000^{\prime}(-20 \mathrm{kt})$ \\
\hline 220 & dial AP ALT to ‘3,000’ (ft) \\
\hline 221 & set AP ALT 'on' \\
\hline \multirow[t]{2}{*}{350} & dial IAS to '150’ (kt) \\
\hline & set flaps down by ' 20 ' \\
\hline 360 & set HNAV and VNAV 'on' \\
\hline 460 & set gear 'down' \\
\hline 525 & set autobrake to ' 4 ' \\
\hline
\end{tabular}
V8.40 SIMULATION MODEL

vertical axes are integer grid indices $I$ and $J$ for the Lambert conformal projection, respectively.

Figure 3 shows the RUC data with the record number 46 for the temperature in Kelvins on the pressure level of $800 \mathrm{mb}$ at the same time as described in Fig. 2.

Figures 4 and 5 show the RUC data for the easterly $(\mathrm{u})$ and northerly $(\mathrm{v})$ wind in $\mathrm{m} / \mathrm{s}$ on the pressure level of $800 \mathrm{mb}$ at the same time as described in Fig. 2. The data record number for $\mathrm{u}$-wind is 128 , and for the v-wind is 129 . Figure 6 is the vector plot for the u-wind and v-wind. Note that the wind turbulence can be notified.

The trajectories of the B747-400 simulated by the X-Plane ${ }^{\circledR}$ V8.40 with the input of the RUC data are shown in Figs. 7 and 8. The flight commands are implemented by using X-Plane's plug-in program that automatically flies the airplane in a circle for takeoff from the runway 22L at the Boston Logan Airport $\left(42.3629722^{\circ},-71.0064167^{\circ}\right)$, in-flight, and ILS landing to the same airport. Figure 7 shows the horizontal paths for the flights 


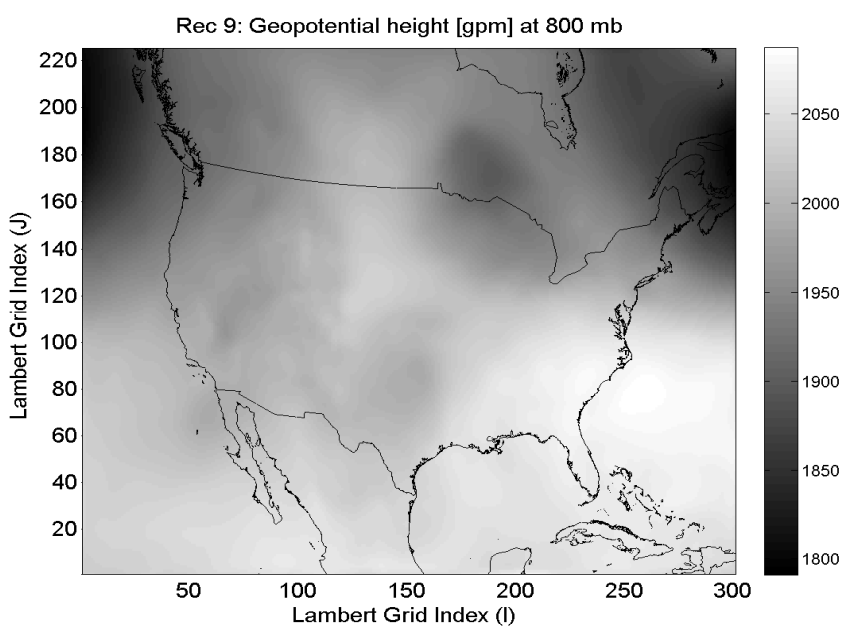

Figure 2. EXAMPLE OF THE RUC DATA FOR THE GEOPOTENTIAL HEIGHT [gpm] ON THE PRESSURE LEVEL OF $800 \mathrm{mb}$ AT UTC TIME 16:00, MAY 1ST, 2007. THE RECORD NUMBER OF THE RUC DATA IS 9. THE COORDINATES ARE LAMBERT GRID INDICES I AND J.

in different weather conditions, including February (dash-dash line, Winter), May (dash-dot line, Spring), August (dot-dot line, Summer), and November (diamond-marker line, Fall), all in the first day of the month starting at UTC time of 16:00. Also shown in the solid curve is the flight path when no RUC data are applied to the X-Plane ${ }^{\circledR}$, nor any wind is set by the $\mathrm{X}$-plane. Correspondingly, the vertical flight paths for different weather conditions are shown in Fig. 8. Notice that, due to the different wind conditions, the airplane lands at a different time. In addition, the airplane reaches different altitudes, most markedly at the time around $200 \mathrm{sec}$, due to fact that the aircraft climbs via the command for a target altitude hence the vertical speeds are different for various head winds.

The air pressure and temperature during the flights are shown in Figs. 9 and 10, respectively. Notice that the pressure follows the trend that it decreases when the altitude increases. Similarly, the temperature is lower at a higher altitude. Also notice that the temperatures on 5/1/2007 (Spring) and 11/1/2007 (Fall) are similar, as expected.

The easterly (u-wind) and northerly (v-wind) winds, the most important factor that affect the flight simulation, are shown in Figs. 11 and 12, respectively. Notice that the absolute value for both the u-wind and v-wind is larger at the higher altitude where the $\mathrm{u}$-winds are positive, indicating that the wind mostly travels from west to east. Also of note is the complexity of the wind distribution, showing the importance of applying the realistic weather data for the aircraft flight simulation.

\section{CONCLUSION}

The aircraft flight simulations are demonstrated with the input of realistic weather parameters retrieved from the Rapid Up-

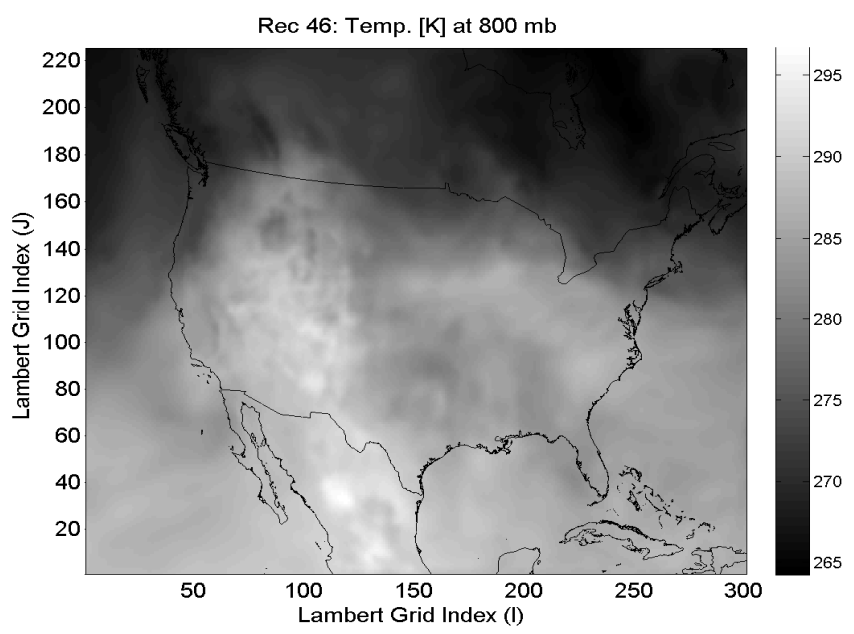

Figure 3. EXAMPLE OF THE RUC DATA FOR THE TEMPERATURE [K] ON THE PRESSURE LEVEL OF $800 \mathrm{mb}$ AT UTC TIME 16:00, MAY 1ST, 2007, WITH THE RUC RECORD NUMBER AS 46.

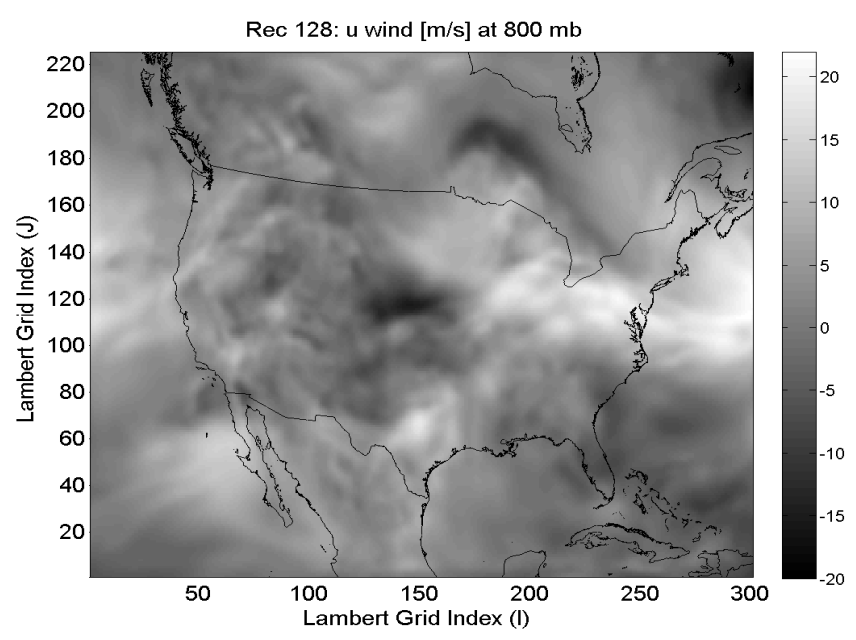

Figure 4. EXAMPLE OF THE RUC DATA FOR THE EASTERLY WIND SPEED (U-WIND)ON THE PRESSURE LEVEL OF $800 \mathrm{mb}$ AT UTC TIME 16:00, MAY 1ST, 2007, WITH THE RUC RECORD NUMBER AS 128, ONE OF THE U-WIND DATA FOR 37 DIFFERENT PRESSURE LEVELS.

date Cycle (RUC) data. The airplane model is the B747-400 automatically commanded by the plug-in program for the $\mathrm{X}$ Plane ${ }^{\circledR}$ V8.40 simulator. The airplane's flight time and geodetic location (latitude, longitude, and altitude) are outputs from the X-Plane ${ }^{\circledR}$ and are used as the inputs for retrieving the RUC data. The algorithms involved in the RUC data processing include solving the pressure as a function of altitude, 2-D data interpolation, and time averaging for any flight time. The resultant RUC data are sent back to the X-Plane ${ }^{\circledR}$ at the rate of one callback in every two seconds through the plug-in program by overwriting X-Plane's reference parameters. Excluding the time 


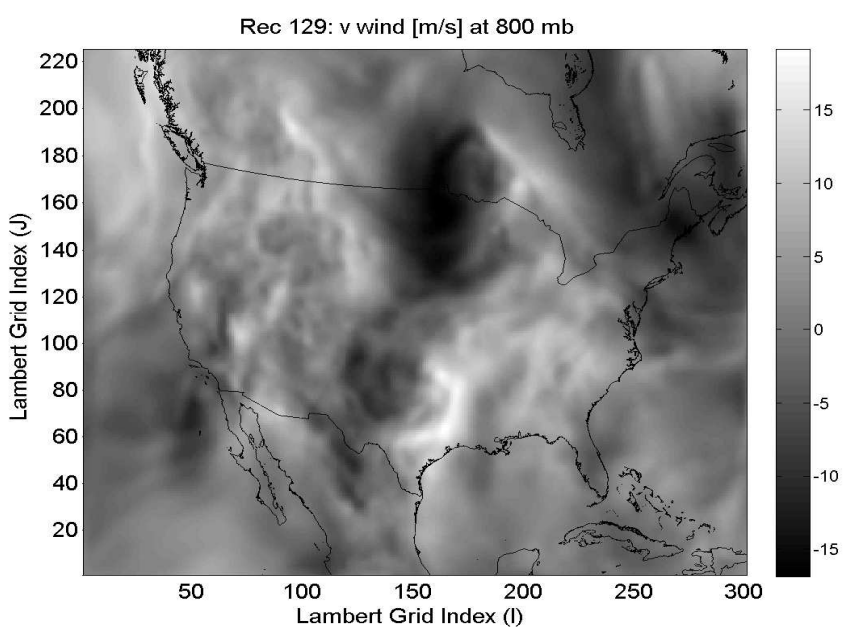

Figure 5. EXAMPLE OF THE RUC DATA FOR THE NORTHERLY WIND SPEED (V-WIND) ON THE PRESSURE LEVEL OF $800 \mathrm{mb}$ AT UTC TIME 16:00, MAY 1ST, 2007, WITH THE RUC RECORD NUMBER AS 129.

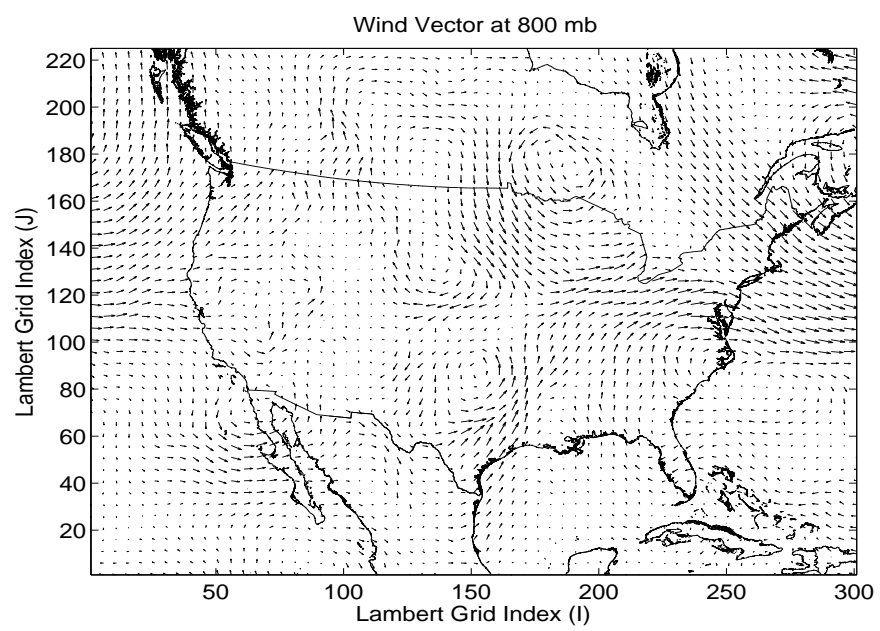

Figure 6. THE VECTOR PLOT BY USING THE MATLAB COMMAND QUIVER() FOR THE U-WIND AND V-WIND ON THE PRESSURE LEVEL OF 800 mb AT UTC TIME 16:00, MAY 1ST, 2007, AS SHOWN IN FIGS. 4 AND 5.

used for downloading the RUC data from the internet, the entire process for the RUC data per callback is about $0.1 \mathrm{sec}$ CPU time.

The simulations show significant changes of the flight paths with the wind retrieved from the RUC data, indicating large variations of the weather conditions in different seasons and sensitive response of the aircraft. The simulations also show the possibility of using the model described in this paper to study hazardous weather conditions for a given flight route, and validate new flight route with the presence of adverse weather conditions recorded in the RUC data. Upon the availability of the forecast RUC data, it is also possible to use the model to make a predic-

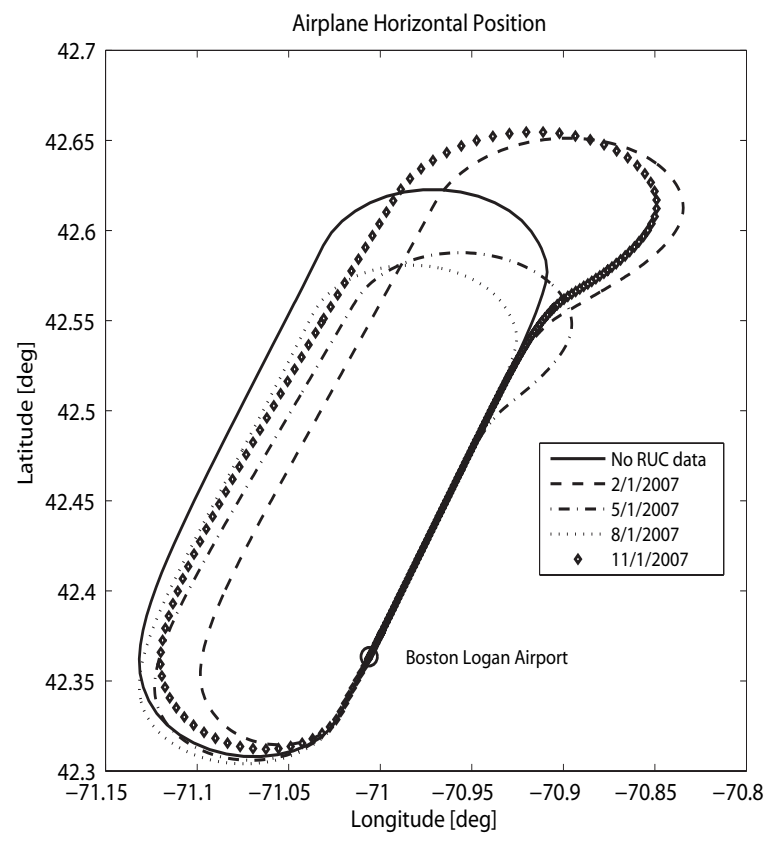

Figure 7. SIMULATION OF B747-400 HORIZONTAL FLIGHT PATHS IN THE CLOCKWISE DIRECTION USING X-PLANE ${ }^{\circledR}$ FOR VARIOUS WIND CONDITIONS. THE AIRPLANE FLIGHTS ARE SIMULATED BY USING X-PLANE ${ }^{\circledR}$ V8.40 WITH THE AUTOPILOT COMMANDS INCLUDING TAKEOFF, IN-FLIGHT, AND ILS LANDING PROGRAMMED IN THE PLUGINS. THE RUNWAY IS CHOSEN AS RUNWAY 22L AT THE BOSTON LOGAN INTERNATIONAL AIRPORT (KBOS).

tion for the safety of a flight path in a future time.

\section{ACKNOWLEDGMENT}

Any opinions, findings, and conclusions or recommendations expressed in this paper are those of the authors. The authors would like to thank Dr. Thomas Seliga and Dr. Frank Wang of the Volpe National Transportation Systems Center, and Mr. Gerard Fairley of EG\&G for their valuable suggestions and comments on this work. The authors also thank Mr. Vincent Orlando of the Volpe Center for his help of operating the X-Plane ${ }^{\circledR}$ flight simulator.

\section{NOMENCLATURE}

$A, B, C$ Coefficients of a linear equation defining a flat surface $A^{\prime}, B^{\prime}, C^{\prime}, D^{\prime}$ Determinants of matrix coefficients for solving a

$C^{\circ} \quad$ Degree Celsius linear equation set

D The RUC data array

$D_{1}, D_{2}, D_{3} \quad$ RUC data at the vertices of triangle grid for Lambert conformal projection

GM Earth's gravitational constant including atmosphere

$H$ Cone orientation number for Lambert conformal projection 


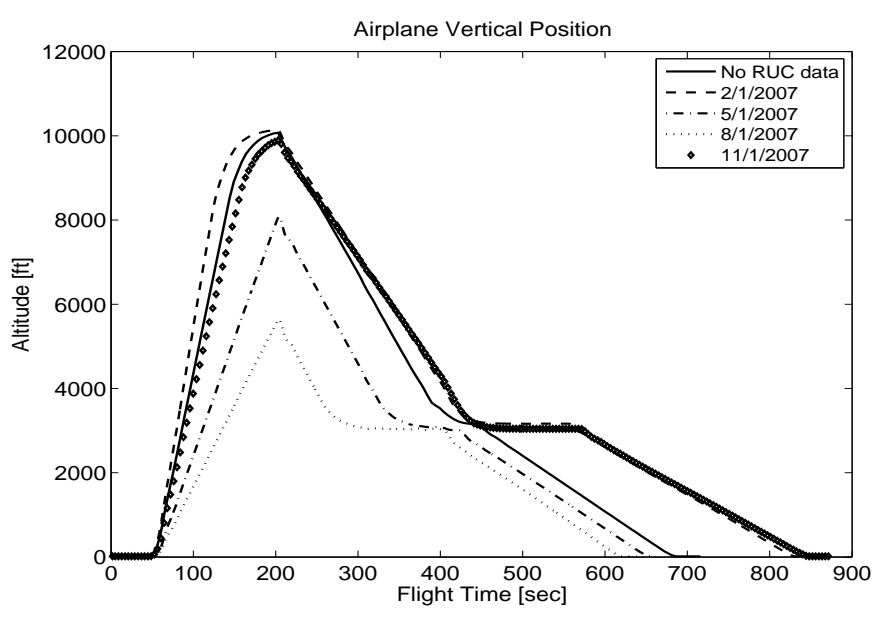

Figure 8. SIMULATION OF B747-400 VERTICAL FLIGHT PATHS USING X-PLANE ${ }^{\circledR}$ IN DIFFERENT MONTHS REPRESENTING VARIOUS SEASONS. THE HORIZONTAL AXIS IS THE TIME OF FLIGHT STARTING AT ZERO, AND THE VERTICAL AXIS IS THE ALTITUDE IN FEET, WHERE $1 \mathrm{ft}=0.3048 \mathrm{~m}$.

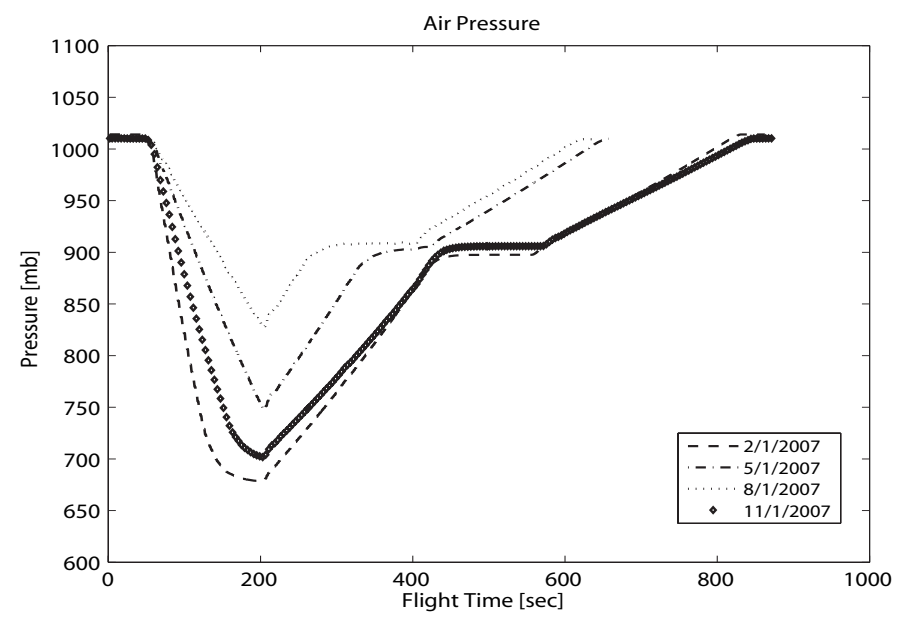

Figure 9. THE AIR PRESSURE CALCULATED FROM THE RUC DATA ALONG THE FLIGHT PATHS SHOWN IN FIGS. 7 AND 8, EXCEPT FOR THE FLIGHT PATH (SOLID LINES) WITH NO RUC DATA. THE HORIZONTAL AXIS IS THE TIME OF FLIGHT STARTING AT ZERO. THE VERTICAL AXIS IS THE PRESSURE IN MILLIBAR $(\mathrm{mb})$, WHERE $1 \mathrm{mb}$ $=100 \mathrm{~N} / \mathrm{m}^{2}$.

$H_{g} \quad$ A function in the theoretical geopotential height model

$I, J$ Index numbers of the RUC data for Lambert conformal projection

$K \quad$ Kelvin for temperature

$R_{0} \quad$ Radius of the spherical Earth

$X, Y, Z$ Cartesian coordinates of the Earth-Centered EarthFixed (ECEF) frame

a Semi-major axis of the ellipsoidal Earth

$b$ Semi-minor axis of the ellipsoidal Earth

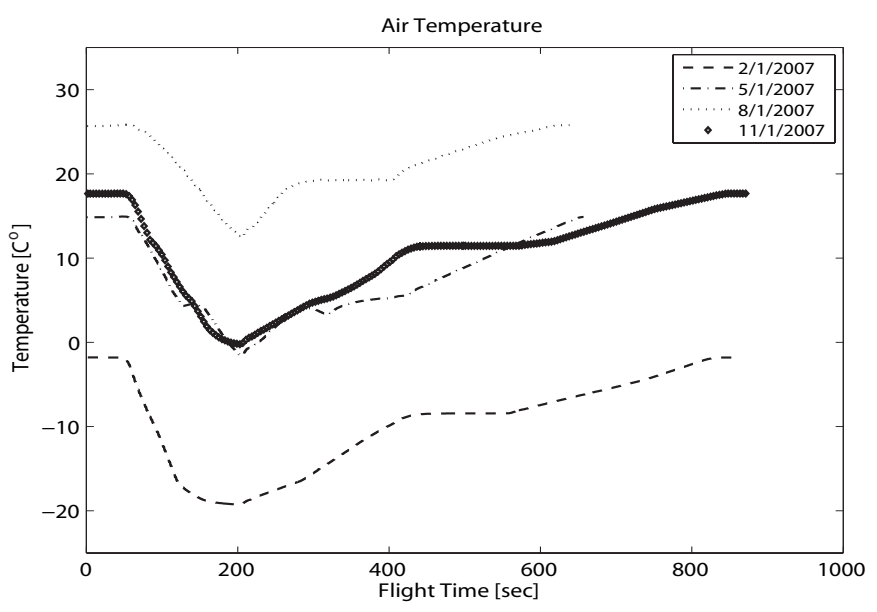

Figure 10. THE AIR TEMPERATURE CALCULATED FROM THE RUC DATA ALONG THE FLIGHT PATHS SHOWN IN FIGS. 7 AND 8, EXCEPT FOR THE FLIGHT PATH WITH NO RUC DATA. THE HORIZONTAL AXIS IS THE TIME OF FLIGHT STARTING AT ZERO, AND THE VERTICAL AXIS IS THE TEMPERATURE IN CELSIUS $\left(\mathrm{C}^{\circ}\right)$.

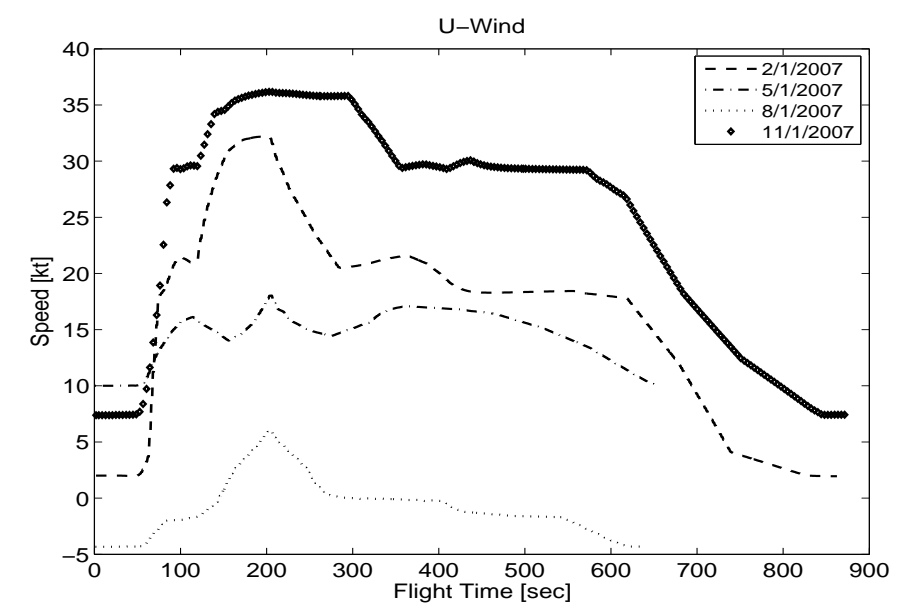

Figure 11. THE EASTERLY WIND (U-WIND) CALCULATED FROM THE RUC DATA ALONG THE FLIGHT PATHS SHOWN IN FIGS. 7 AND 8, EXCEPT FOR THE FLIGHT PATH WITH NO RUC DATA. THE HORIZONTAL AXIS IS THE TIME OF FLIGHT STARTING AT ZERO, AND THE VERTICAL AXIS IS THE WIND SPEED IN KNOTS (kt), WHERE $1 \mathrm{kt}=$ $0.5144444 \mathrm{~m} / \mathrm{s}$.

deg Degree temperature

deg-ang Degree angle

$d x, d y \quad$ Grid length in $x$ and $y$-direction for Lambert conformal projection

$e$ Eccentricity of the ellipsoidal Earth

$f$ Flattening of the ellipsoidal Earth

ft Feet

$g$ Gravitational acceleration on the surface of the ellipsoidal 


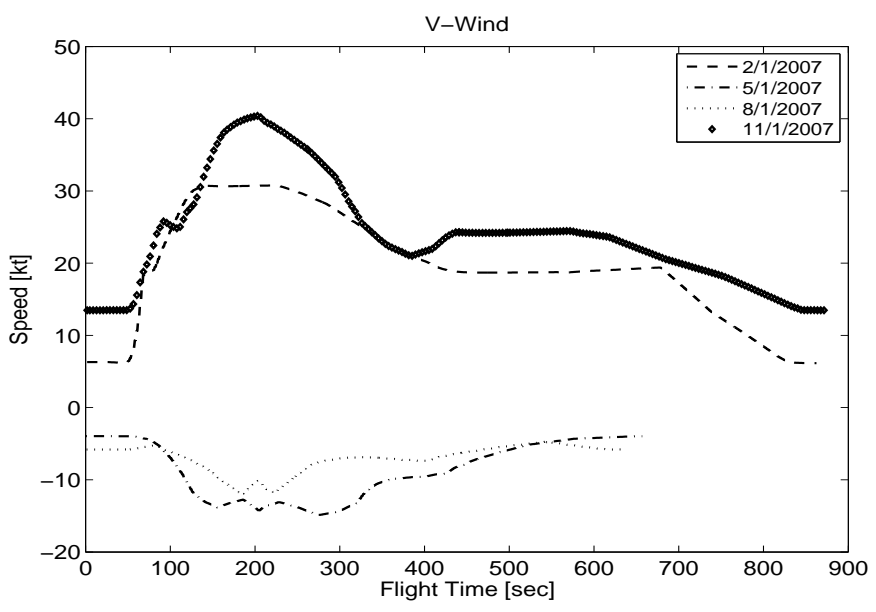

Figure 12. THE NORTHERLY WIND (V-WIND) CALCULATED FROM THE RUC DATA ALONG THE FLIGHT PATHS SHOWN IN FIGS. 7 AND 8, EXCEPT FOR THE FLIGHT PATH WITH NO RUC DATA. THE HORIZONTAL AXIS IS THE TIME OF FLIGHT STARTING AT ZERO, AND THE VERTICAL AXIS IS THE WIND SPEED IN KNOTS (kt).

Earth

$g_{0} \quad$ Standard gravity at the mean sea level

$g_{e}$ Gravitational acceleration at the equator

$g_{p} \quad$ Gravitational acceleration at the poles

gpm Geopotential meters

$h$ Geodetic altitude

$h_{0} \quad$ Geoid undulation

$h_{g} \quad$ The RUC geopotential height

$\tilde{h}_{g} \quad$ The theoretical geopotential height

$i, j$ Index numbers of an arbitrary point for Lambert conformal projection

$k$ A factor for the theoretical geopotential model

kt knots for velocity

$\ell$ Index for RUC pressure level

$m$ Meters

$m b$ Millibars

$m / s \quad$ Meters per second

$m / s^{2} \quad$ Meters per square second

$\mathrm{N} / \mathrm{m}^{2} \quad$ Newton per square meter

$n^{*}$ Constant of the cone for Lambert conformal projection

$p$ The air pressure of the RUC data

$p_{\ell} \quad$ The air pressure of the RUC data at level $\ell$

$r$ Location ratio for 2-D interpolation

$t$ Aircraft flight simulation time

$t_{n} \quad$ The RUC time at $n$-th hour in the day

$t_{n+1} \quad$ The RUC time at $(n+1)$-th hour in the day

$x_{1}, y_{1}$ Local coordinates for the left lower pixel for Lambert conformal projection

$\alpha$ Weighting factor for averaging the RUC data in time

$\chi$ Constant in geodetic coordinate system

$\lambda$ Geodetic longitude

$\lambda^{\prime}$ Geocentric longitude $\lambda_{0}^{\prime}$ Geocentric longitude of the reference meridian for Lambert conformal projection

$\lambda_{1}^{\prime}$ Geocentric longitude of the first point for Lambert conformal projection

$\omega$ Angular velocity of the Earth

$\Phi$ Gravitational potential

$\phi$ Geodetic latitude

$\phi^{\prime}$ Geocentric latitude

$\phi_{0}^{\prime} \quad$ Geocentric latitude of the tangent point for Lambert conformal projection

$\phi_{1}^{\prime}$ Geocentric latitude of the first point for Lambert conformal projection

$\rho$ Radius for Lambert conformal projection

$\sigma_{1}$ Image scale for Lambert conformal projection

$\theta$ Polar angle for Lambert conformal projection

$\theta$ Universal Time, Coordinated

\section{REFERENCES}

[1] McGovern, S. M., 2007. National Airspace System Stochastic Simulation Aircraft Model Validation Survey. DOT-RITA-RTV-4B-07-03-1.0, May.

[2] Zhang, Y., and McGovern, S., 2008. Geodetic Height Retrieval from the Rapid Update Cycle (RUC) Data for Aircraft Fligth Simulation. Submitted for publication, Feb.

[3] Zhang, Y., and McGovern, S., 2008. Atmospheric Pressure Calculation for Given Aircraft Geodetic Locations by Using the Rapid Update Cycle (RUC) Data. Submitted for publication, Feb.

[4] URL http: / / ruc.noaa.gov.

[5] Hofmann-Wellenhof, B., and Moritz, H., 2005. Physical Geodesy. Springer Wien, New York.

[6] Stackpole, J. D., 1994. A Guide to GRIB. Technical Report 1st edition, NOAA National Weather Service, Feb.

[7] URL http: // nomads . ncdc.noaa.gov.

[8] URL http://www. cpc.ncep.noaa.gov/produc ts/wesley/wgrib.html.

[9] Hoke, J. E., Hayes, J. L., and Renninger, L. G., 1981. Map Projections and Grid Systems for Meteorological Applications. AFGWC/TN-79/003, March.

[10] Unknown, 2000. Department of Defense World Geodetic System 1984. NIMA TR8350.2, 3rd edition, Cambridge, MA, Jan.

[11] URL http: / / www . mathworks. com.

[12] URL http://www.x-plane.com.

[13] URL http: / / www . xs quawkbox. net. 